\title{
Excitation thresholds of field-aligned irregularities and associated ionospheric hysteresis at very high latitudes observed using SPEAR-induced HF radar backscatter
}

\author{
D. M. Wright ${ }^{1}$, R. S. Dhillon ${ }^{1}$, T. K. Yeoman ${ }^{1}$, T. R. Robinson ${ }^{1}$, E. C. Thomas ${ }^{1}$, L. J. Baddeley ${ }^{1,2}$, and S. Imber ${ }^{1,3}$ \\ ${ }^{1}$ Department of Physics and Astronomy, University of Leicester, University Road, Leicester LE1 7RH, UK \\ ${ }^{2}$ Department of Geophysics, The University Centre in Svalbard (UNIS), P.O. Box 156, 9171 Longyearbyen, Norway \\ ${ }^{3}$ NASA Goddard Space Flight Center, Greenbelt, MD, 20771, USA
}

Received: 14 November 2008 - Revised: 5 June 2009 - Accepted: 8 June 2009 - Published: 1 July 2009

\begin{abstract}
On 10 October 2006 the SPEAR high power radar facility was operated in a power-stepping mode where both CUTLASS radars were detecting backscatter from the SPEAR-induced field-aligned irregularities (FAIs). The effective radiated power of SPEAR was varied from 1-10 MW. The aim of the experiment was to investigate the power thresholds for excitation $\left(P_{t}\right)$ and collapse $\left(P_{c}\right)$ of artificiallyinduced FAIs in the ionosphere over Svalbard. It was demonstrated that FAI could be excited by a SPEAR ERP of only $1 \mathrm{MW}$, representing only 1/30th of SPEAR's total capability, and that once created the irregularities could be maintained for even lower powers. The experiment also demonstrated that the very high latitude ionosphere exhibits hysteresis, where the down-going part of the power cycle provided a higher density of irregularities than for the equivalent part of the up-going cycle. Although this second result is similar to that observed previously by CUTLASS in conjunction with the Troms $\emptyset$ heater, the same is not true for the equivalent incoherent scatter measurements. The EISCAT Svalbard Radar (ESR) failed to detect any hysteresis in the plasma parameters over Svalbard in stark contract with the measurements made using the Troms $\varnothing$ UHF.
\end{abstract}

Keywords. Ionosphere (Active experiments; Ionospheric irregularities; Polar ionosphere)

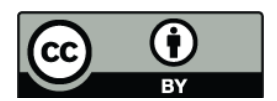

Correspondence to: D. M. Wright

(darren.wright@ion.le.ac.uk)

\section{Introduction}

The artificial modification of the Earth's ionosphere was first noted in the 1930s when newly built broadcast radio stations began operations. Radio signals propagating through the region of the ionosphere modified by the high power radio waves were influenced through a cross modulation effect (Tellegen, 1933; Bailey and Martyn, 1934). The first purpose-built high power transmitters (or heaters), intended for ionospheric studies, appeared in the 1970s and the first reported ionospheric modification (heating) experiments were performed at Platteville, Colorado. These experiments revealed that the high power "pump" wave led to the generation of field-aligned electron density irregularities (FAIs; Fialer, 1974; Minkoff et al., 1974). The FAIs are excited as a result of the coupling of the pump wave to a type of electrostatic plasma waves known as upper hybrid (UH) waves which occur in a narrow altitude region around the upper hybrid height. These UH waves cause an enhancement in the electron temperature, hence the term "heating". After several tens of seconds the electron density in the active region increases due to the temperature dependence of the recombination. However, in the upper F-region (about $\sim 200 \mathrm{~km}$ ) other processes can also lead to density depletions (Gurevich, 1978; Ashrafi et al., 2006). Detailed discussions on the excitation of FAIs and other heater-induced phenomena are given in the reviews by Robinson (1989) and Stubbe (1996). Once they exist, the heater-induced FAI provide intense and coherent targets for HF radars such as CUTLASS, which receive backscatter from field-aligned electron density irregularities (e.g. Robinson, 1997).

Published by Copernicus Publications on behalf of the European Geosciences Union. 


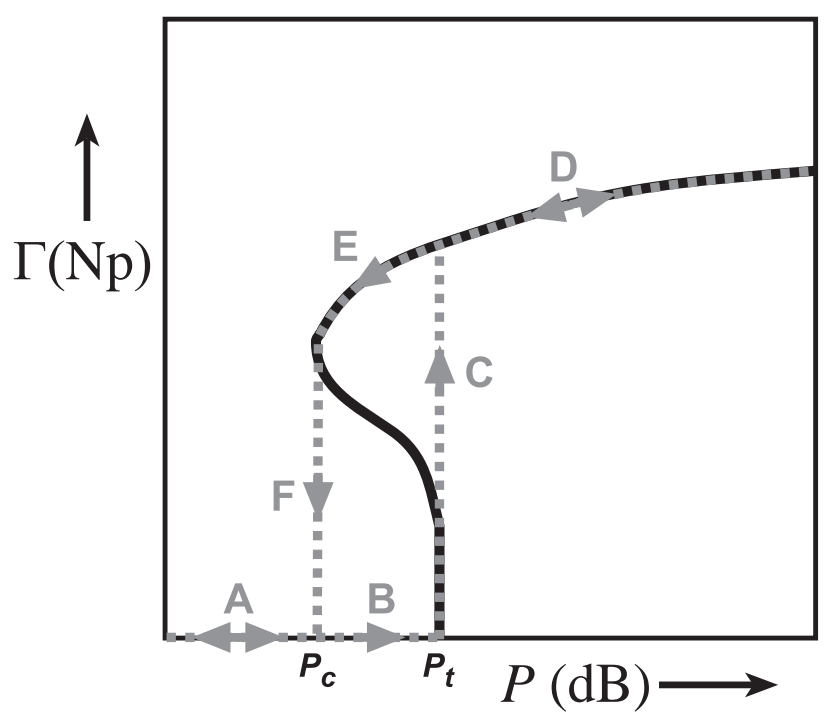

Fig. 1. A theoretical curve showing the relationship between anomalous absorption and heater power (solid curve). The dashed lines show the different paths that lead to the hysteresis effect.

Current theory suggests that the FAI are generated by the thermal parametric instability (TPI). There are two regimes of the TPI which relate to soft and hard excitation, depending on whether initial density perturbations are infinitesimal or finite respectively (e.g., Istomin and Leyser, 1997). The former regime corresponds to the thermal oscillating twostream instability (TOTSI; e.g. Grach et al., 1978; Dysthe et al., 1983) while the latter regime is the resonance instability reported by Vaskov and Gurevich (1977). The nonlinear stage of the soft regime resembles the resonance instability. The TOTSI is a well-known theory for the creation and rapid growth of FAIs and one which readily explains the radar observations (e.g. Robinson, 1997).

Initially, the TOTSI causes a linear conversion of electromagnetic pump wave energy into upper hybrid waves (Vaskov and Gurevich, 1977; Dysthe et al., 1983; Robinson, 1988). This coupling requires the presence of plasma density gradients (pre-existing FAIs) and leads to an increase in the FAI amplitude. Once this amplitude exceeds a threshold value (typically after a few milliseconds) the interaction becomes nonlinear and the irregularity amplitude increases explosively. A simple heuristic (or fitting) model (Dysthe et al., 1983; Robinson, 1989) leads to a relationship between the pump power, $P$, and the level of anomalous absorption, $\Gamma$, experienced by the pump wave, given by

$P\left[e^{-\Gamma / 2} \frac{1-(\cosh (\Gamma / 2)-1)(\ln a) / \pi}{P_{1}}+\frac{\Gamma e^{\left(\Gamma_{0}-\Gamma\right) / 4}}{\Gamma_{0} P_{2}}\right]=1$,

where $P_{1}$ and $P_{2}$, respectively, are the required power thresholds for the initial and explosive stages of FAI growth, $\Gamma_{0}$ is the level of anomalous absorption before the heater was activated and $a$ is a factor relating to the field parallel scale length of the FAIs (see Robinson, 1989). The two terms in Eq. (1) represent the initial and explosive instabilities. Since anomalous absorption $\Gamma \propto n^{2}$, where $n$ is the FAI amplitude, then irregularity saturation as governed by Eq. (1) is illustrated as the solid curve in Fig. 1 in which $\Gamma$ is plotted as a function of $P$.

Hysteresis effects in the ionospheric plasma are a consequence of a thermal parametric instability such as the TOTSI (e.g. Grach et al., 1978). The existence of hysteresis was confirmed by the ionospheric modification experiments at Gorkii in Russia reported by Erukimov et al. (1978) and subsequently by Stubbe et al. (1982) and Jones et al. (1983) using the heating facility at Troms $\varnothing$. A hysteresis effect occurs in the generation of FAI because a threshold power, $P_{t}$, (shown in Fig. 1) required for the onset of FAI growth is higher than the critical pump power, $P_{c}$, at which the FAI can no longer be sustained and, hence, collapse. The effective threshold power is given by

$P_{t}=\frac{P_{1} P_{2}}{P_{1}+P_{2}}$,

where $P_{t}$ is larger than both $P_{1}$ and $P_{2}$. So, once the heater power $P>P_{t}$ then the FAI form explosively and saturation is rapid. This is demonstrated in Fig. 1 by the path $A B C D$. If the pump power is then steadily reduced, the FAI do not collapse until $P<P_{c}$, therefore following path $D E F A$.

This paper concerns the excitation and hysteresis of FAI induced by the SPEAR (Wright et al., 2000; Robinson et al., 2006) high power heating facility, located on Spitsbergen. Since SPEAR is the most northerly heating facility in the world, these observations have never been possible before at these very high latitudes $\left(75^{\circ} \mathrm{N}\right.$ geomagnetic, $\left.L \sim 15\right)$. Similar experiments have been undertaken at lower latitudes. In particular, this study will compare observations over SPEAR with those in the vicinity of the EISCAT Heater near Troms $\varnothing$, Norway $\left(66^{\circ} \mathrm{N}\right.$ geomagnetic, $\left.L \sim 6.6\right)$, and presented by Wright et al. (2006). It will be shown that FAIs can be artificially excited using very low effective radiated powers (ERPs) from SPEAR. Hysteresis effects are clearly observed in the CUTLASS radar backscatter from both Troms $\varnothing$ and SPEAR. However, stark differences are apparent in the incoherent scatter measurements provided by the EISCAT UHF radars.

\section{Instrumentation}

\subsection{The SPEAR high power facility}

SPEAR (Space Plasma Exploration by Active Radar; Wright et al., 2000; Robinson et al., 2006) is a facility capable of radiating high power radio waves in the high frequency (HF) band in the range $4-6 \mathrm{MHz}$. It was deployed on the island of Spitsbergen (in the Svalbard archipelago) at a geographic latitude of $78^{\circ} \mathrm{N}\left(75^{\circ} \mathrm{N}\right.$ geomagnetic; $\left.L \sim 15\right)$ and 


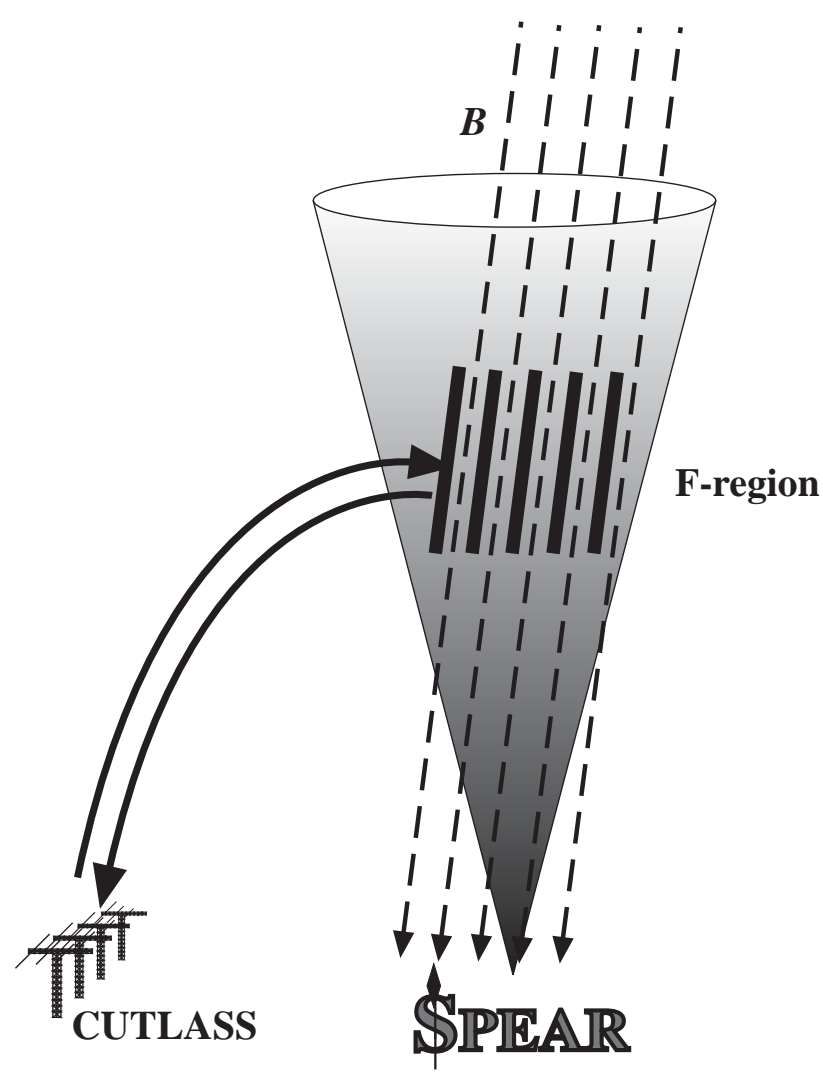

Fig. 2. A schematic representation of field-aligned irregularity generation by a high power heater and a half-hop radio path of an $\mathrm{HF}$ radar which receives backscatter from these structures.

is collocated with the EISCAT Svalbard Radar (ESR). First operations occurred in 2003. SPEAR utilises direct digital synthesis (DDS) technology to be able to point its beam in any direction essentially instantaneously. It currently employs a $4 \times 6$ array of rhombically broadened dipole antennas and possesses a frequency-dependent beam width which is approximately $14^{\circ} \times 21^{\circ}$ wide with a gain of $21 \mathrm{dBi}$ (Wright et al., 2000). During the experiment described in this paper, SPEAR was operated at a frequency of $4.45 \mathrm{MHz}$ with O-mode polarisation and stepped its power output up to a maximum ERP of $10 \mathrm{MW}$. The SPEAR beam was directed along the magnetic field.

O-mode polarised radio waves radiated by SPEAR are capable of interacting with the ionospheric plasma and can couple to upper hybrid waves, as described above, to excite FAI. When the ionosphere is underdense, the radio waves radiated by SPEAR can also interact with plasma deeper in the magnetosphere. In addition, SPEAR operates not only as an ionospheric heating facility but also possesses a receiving system and can thus also function as a radar. First results and more detailed description of various SPEAR experiments are presented by Robinson et al. (2006).
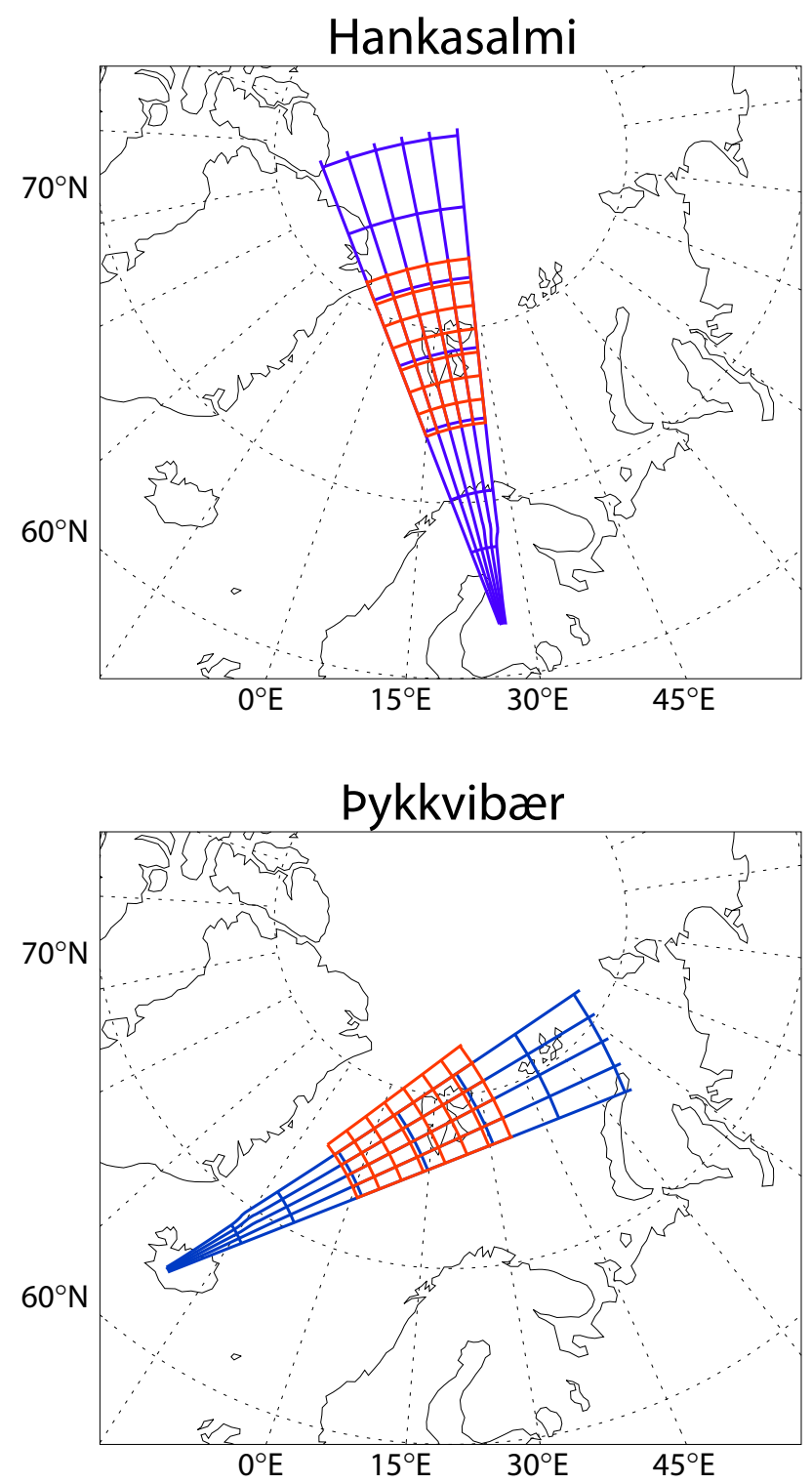

Fig. 3. A map illustrating the beam patterns employed by the CUTLASS radars during this experiment. The two fields of view of the radars are made possible by operating each radar in its stereo mode. Along the radar beams the range is marked every 10 range gates.

\subsection{The CUTLASS radars}

The global SuperDARN radar network (Greenwald et al., 1995) currently consists of $19 \mathrm{HF}$ coherent radars, 12 of which operate in the Northern Hemisphere. Two of the Northern Hemisphere SuperDARN radars comprise the CUTLASS (Co-operative UK Twin Located Auroral Sounding System) system. CUTLASS is a frequency agile bistatic HF radar system (e.g. Milan et al., 1997) operating in the range $8-20 \mathrm{MHz}$ and consisting of stations at Pykkvibær, Iceland and Hankasalmi, Finland. The signals returned to the radars have undergone a Bragg-like backscattering process 


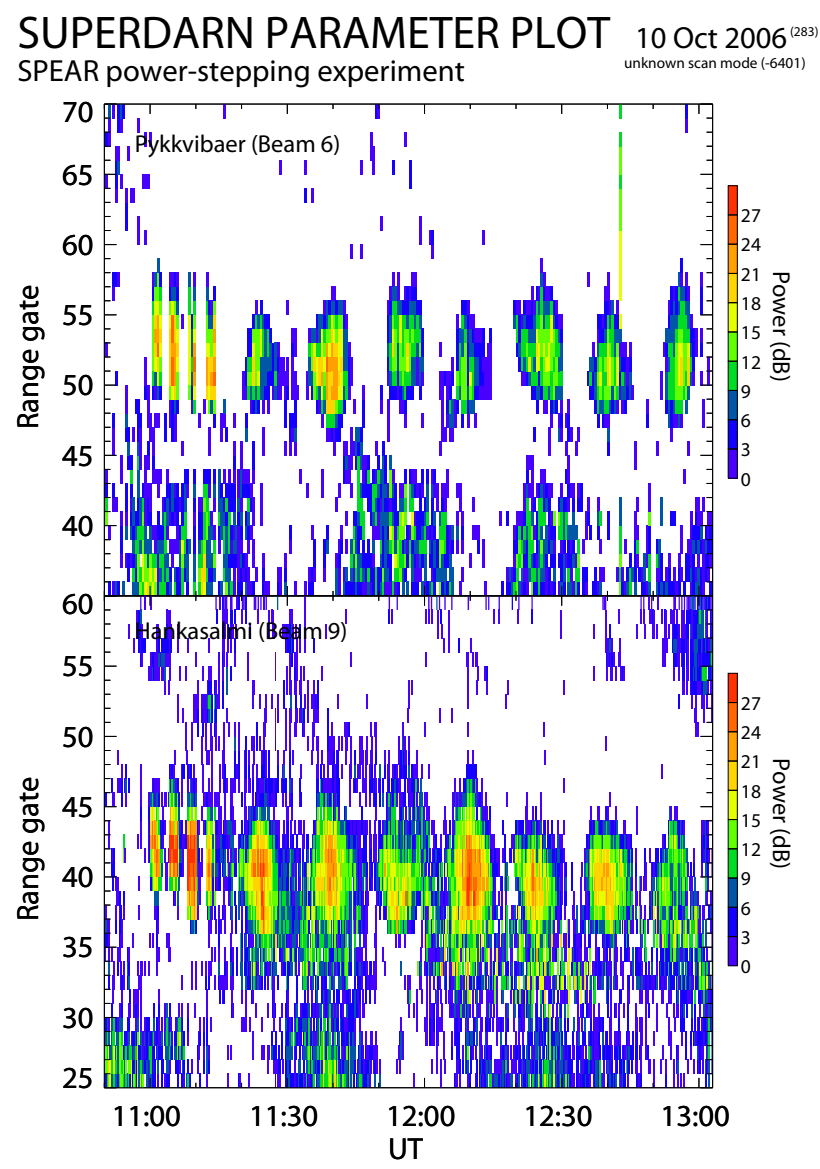

Fig. 4. Backscatter power (pwr_l) measurements from the CUTLASS Hankasalmi (upper panel) and Pykkvibær (lower) radars during the power stepping experiment utilising SPEAR on 10 October 2006 .

from FAIs in the ionosphere. There is an aspect-angle dependence for scattering, which requires that the radio wave $\boldsymbol{k}$ vector is close to orthogonal to the magnetic field. The experiments described here utilise the SPEAR high power HF Heating facility which can generate artificial field-aligned irregularities as described earlier and thus provide a region of backscatter in the CUTLASS fields of view (e.g. Robinson et al., 1997) when backscatter may not already be present. This effect is illustrated schematically in Fig. 2. The detection of artificial backscatter by HF radar then provides a powerful way of diagnosing plasma processes (e.g. Robinson et al., 1997) and observing geophysical phenomena (e.g. Yeoman et al., 1997).

During the experiments relevant to this paper, the CUTLASS radars operated in "stereo" mode where, by utilising some of the radar's spare duty cycle, each radar was able to simultaneously sound over two different scan patterns. These are shown on the maps illustrated in Fig. 3. In their standard operational mode the radars would sweep over 16 beams with a dwell time of 3 or $7 \mathrm{~s}$ on each beam and a range

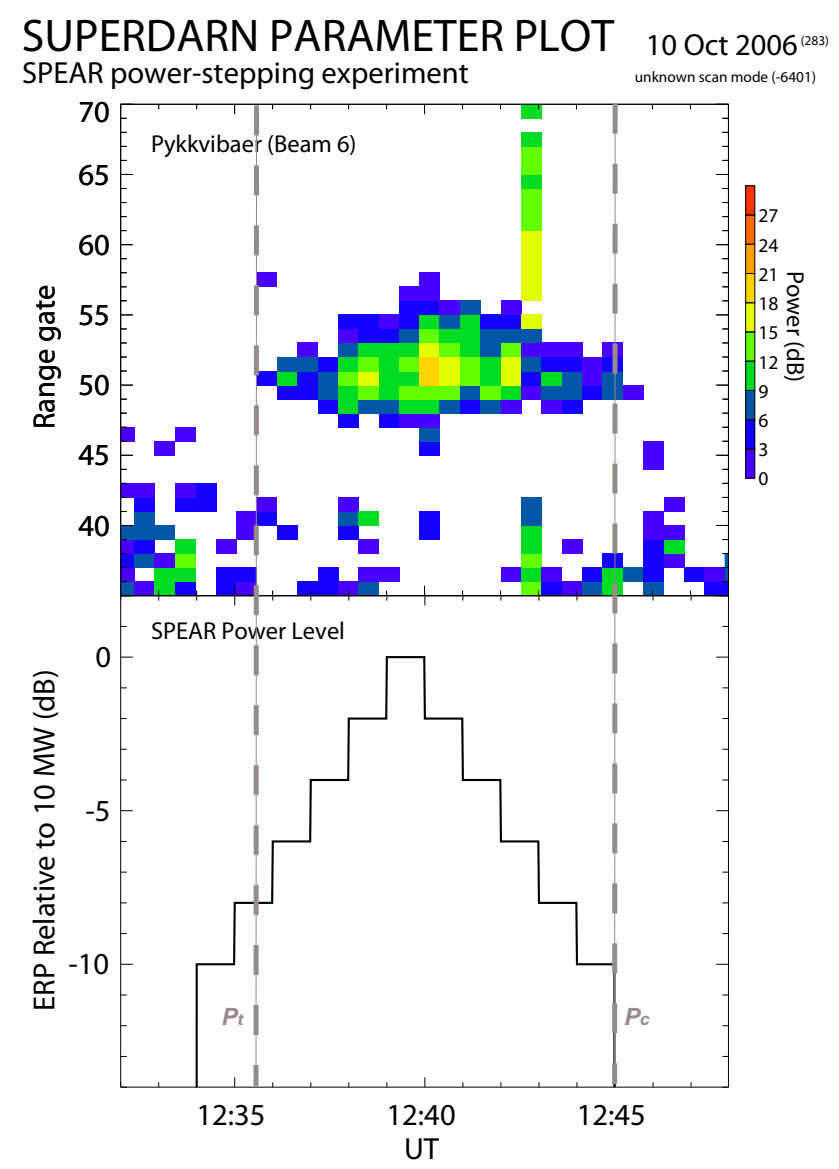

Fig. 5. Backscatter power (pwr_l) measurements from the CUTLASS Pykkvibær radar (upper) during one power stepping cycle on 10 October 2006. The SPEAR output power during the interval is shown in the lower panel.

resolution of $45 \mathrm{~km}$. During this experiment, however, the radars were sounding over reduced regions, the blue and red fields of view indicating the two scan patterns. Only data for the red fields of view (centred over SPEAR) are considered in this paper. The first range sounded on both the Hankasalmi and Pykkvibær radars was $1485 \mathrm{~km}$. SPEAR lies at approximately $1800 \mathrm{~km}$ from the Hankasalmi radar and about $1900 \mathrm{~km}$ from Pykkvibær. The dwell (integration) time on each radar beam was $1 \mathrm{~s}$ for Hankasalmi and $2 \mathrm{~s}$ for Pykkvibær. Each radar scanned over 5 beams in the red field of view and employed a three frequency scan mode during this experiment. Thus the final time resolution of the radar data for a single beam and a narrow frequency band (12.3$12.6 \mathrm{MHz}$ for all the data shown here) is $15 \mathrm{~s}$ for Hankasalmi and $30 \mathrm{~s}$ for Pykkvibær. The high backscatter powers that are characteristic of artificially generated irregularities make it possible to integrate data over such short dwell times since the signal to noise levels are high. Only data from beam 9 of the Hankasalmi radar and beam 6 of Pykkvibær have been employed as these beams overlie the location of SPEAR. 


\subsection{The EISCAT Svalbard Radar (ESR)}

The EISCAT Svalbard radar system (ESR; Wannberg et al., 1997) is collocated with SPEAR and was used to detect SPEAR-enhanced incoherent radar backscatter from which plasma parameters, such as electron concentration and ion and electron temperatures, may be derived. The ESR operates at frequencies close to $500 \mathrm{MHz}$ and is therefore sensitive to $30 \mathrm{~cm}$ wavelength plasma waves. On 10 October 2006, the ESR ran an experimental mode that used the steerable $32 \mathrm{~m}$ dish (pointed field-aligned, i.e. with a geographic azimuth of $182.1^{\circ}$ and a geographic elevation of $81.6^{\circ}$ ) to collect ion line data using long pulses. Although the ion line spectra were obtained on two channels with transmitter frequencies of 499.9 and $500.3 \mathrm{MHz}$, only data from the $499.9 \mathrm{MHz}$ channel have been presented in this paper. The height-discriminated ion line data, which had a temporal resolution of $5 \mathrm{~s}$, were obtained over an altitude range of 86$481 \mathrm{~km}$ with a resolution of approximately $28 \mathrm{~km}$.

\section{Observations}

On 10 October 2006 SPEAR was operated such that its output power was increased stepwise up to an ERP of $10 \mathrm{MW}$ and then stepped back down. The power, with respect to $10 \mathrm{MW}$, was varied from $-10 \mathrm{~dB}$ to $0 \mathrm{~dB}$ and back to $-10 \mathrm{~dB}$ in $2 \mathrm{~dB}$ steps with a dwell of $1 \mathrm{~min}$ at each power level. This cycle was repeated several times. A gap of four minutes was left between cycles to prevent the preconditioning of the ionosphere from influencing subsequent measurements. A complete cycle, including off period, thus lasted $15 \mathrm{~min}$. Figure 4 shows range-time-intensity (RTI) plots of the received backscatter power at Pykkvibær (upper panel) and Hankasalmi (lower panel) during the experiment. The data presented are for the radar beams which overlie SPEAR and the ESR. At the beginning of the interval shown SPEAR was operated a few times at full power for a few minutes on then off in order to identify the SPEAR-induced backscatter in the CUTLASS radars in real time. Then, at 11:19 UT the first of seven consecutive power-stepping cycles commenced. The backscatter were detected by both CUTLASS radars simultaneously although the SPEAR-induced scatter at Hankasalmi, which appear as the patches of higher intensity in the plots, were embedded in a region of weak natural scatter. Hence, the rest of this paper will focus on the Pykkvibær data where interpreting the weakest returns is more straightforward. Reproduced in the top panel of Fig. 5 are the Pykkvibær data during one of the cycles, selected since it is one of the clearest and simplest examples. The vertical coloured stripe immediately before $12: 43$ UT is most likely caused by noise or interference in the radar data. The lower panel shows the SPEAR output ERP relative to the maximum power of $10 \mathrm{MW}$. The patch of scatter can clearly be seen to intensify as the SPEAR output increases and then fall again as expected. However, with respect to the peak SPEAR output the observed shape and intensity of the patch of artificial scatter is clearly asymmetric. This is indicative of ionospheric hysteresis, where the backscatter intensity is higher for the power-down cycle than for the power-up cycle at the same SPEAR output power. Essentially, SPEAR has preconditioned the ionosphere prior to the down-going part of the power cycle. The two vertical dashed lines are placed in an attempt to indicate the cut-offs of the scatter observed by the radar. $P_{t}$ is related to the power threshold for the explosive excitation of the SPEAR-induced irregularities. It can be seen that $P_{t}$ occurs at about $8 \mathrm{~dB}$ below the maximum (equivalent to an ERP of about 1.6 MW). It seems that the threshold power to prevent collapse of the irregularities $\left(P_{c}\right)$ was below the minimum power $(\sim 1 \mathrm{MW})$ employed during this experiment. It should be noted that the CUTLASS radars may be desensitised to very weak backscatter returns as a result of absorption losses along the $\sim 4000 \mathrm{~km}$ radio wave path between the radar and target and back again. If observed locally, the power thresholds might actually be smaller.

\section{Discussion}

Wright et al. (2006) reported results from a series of powerstepping experiments which were undertaken in 1997 using the Troms $\varnothing$ heating facility in conjunction with the EISCAT mainland UHF radar and CUTLASS. The programme was designed to investigate power thresholds for the creation of FAIs and the associated ionospheric hysteresis. The findings of Wright et al. (2006) will be used for comparison with the observations presented here. Following the commissioning phase of SPEAR, it was decided to run similar experiments to those using the Troms $\varnothing$ heater in order to assess the nature of FAI formation at very high latitudes.

The power-stepping experiments which took place in Troms $\emptyset$ in 1997 demonstrated that artificial FAI could be excited with relatively low heater output powers and that hysteresis played a role in maintaining them. However, the Troms $\emptyset$ heater had a maximum ERP of $155 \mathrm{MW}$ during those experiments and was configured such that the smallest power increment available was 3.9 MW. Wright et al. (2006) could only conclude that the power thresholds $P_{t}$ and $P_{c}$ were less than 3.9 MW. In 2006, SPEAR operated such that it employed a finer step-size during the experiment. The results presented here strongly indicate that the threshold for creating the artificial FAI $\left(P_{t}\right)$ lies in the range 1.0-1.6 MW. Once created, the FAI can be maintained with much weaker powers. Indeed the true value of $P_{c}$ was still outside of the resolution of this experiment. It is only possible to say that $P_{c}<1 \mathrm{MW}$. The marked difference between $P_{t}$ and $P_{c}$ is caused by the irregularity density function given in Fig. 1. The electric field, $E(\mathrm{~V} / \mathrm{m})$, generated by a heater with an 


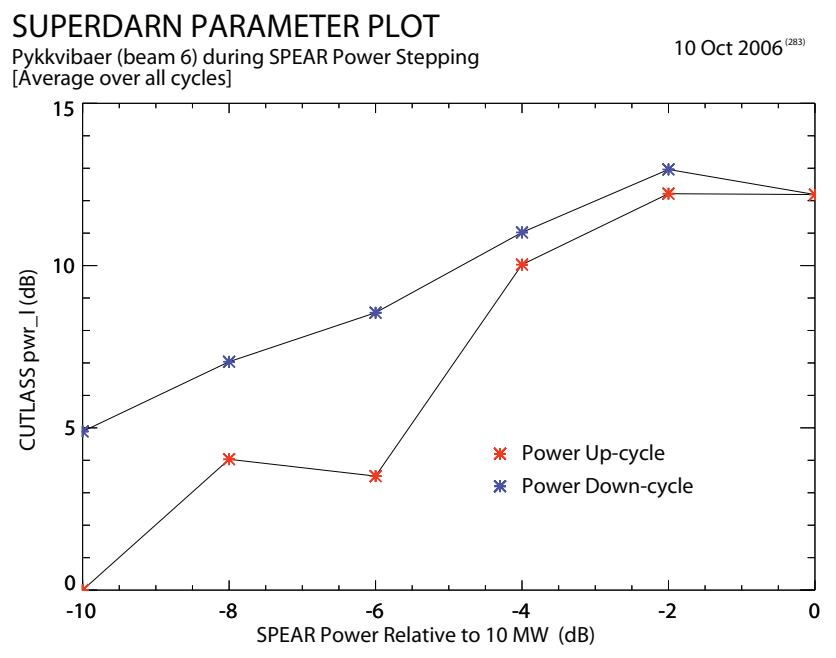

Fig. 6. The backscatter power received by the Pykkvibær radar averaged over all seven SPEAR power cycles. Data for the up-going and down-going parts of the cycle are plotted in red and blue respectively. The error bars associated with each data point are less than $\pm 1 \mathrm{~dB}$.

output ERP $(\mathrm{kW})$ at a given altitude, $R(\mathrm{~km})$, above the heater is given by (Robinson, 1989)

$E=\frac{0.25 \sqrt{\mathrm{ERP}}}{R}$.

The heater interaction altitude (at which the FAI are excited), $R$, was determined to be $158 \mathrm{~km}$ for this experiment (see below). Hence the threshold ERP, $P_{t}$, of $1 \mathrm{MW}$ equates to a threshold electric field, $E_{t}$, of $50 \mathrm{mV} / \mathrm{m}$. This is slightly greater than predicted thresholds (e.g. Istomin and Leyser, 1997).

When SPEAR was constructed concerns were raised that the maximum ERP achievable, being only $\sim 10 \%$ of the heater at Troms $\varnothing$, might not be adequate to artificially excite FAI. Not only was that shown not to be the case by Robinson et al. (2006) but the results presented here also indicate that SPEAR ERPs of only 1/30th of its nominal maximum capability can excite the FAIs. Thus SPEAR offers an opportunity to study the formation of FAIs on fine power scales. In addition, forthcoming experiments will attempt to ascertain the true value of $P_{c}$.

Understanding the observed ionospheric hysteresis utilising SPEAR is far less straightforward. To examine the observed hysteresis, the CUTLASS radar backscatter powers from the centre of each heated patch (the patches move slightly within the radar field of view as a result of natural ionospheric variability along the radar radio wave path) have been separated into up- and down-going parts of the cycle and plotted as a function of SPEAR ERP. Figure 6 shows the average effect over all seven cycles. This clearly demonstrates that ionospheric hysteresis is influencing the CUTLASS radar measurements since the power at a given ERP is higher on the down-going part of the cycle as a result of the preconditioning of the ionosphere over SPEAR. These observations are very similar to those presented by Wright et al. (2006) following the Troms $\varnothing$ experiments except that for the current study the difference in the up- and down-going power levels is significantly smaller. The largest difference in powers observed in Fig. 6 is $5 \mathrm{~dB}$ whereas at Troms $\varnothing$ that difference was nearer $20 \mathrm{~dB}$ at equivalent ERPs. Since the two experiments were conducted at similar points in the solar cycle then perhaps it is likely that the preconditioning inflicted on the ionosphere by the Troms $\varnothing$ heater was much greater (due to the order of magnitude difference in maximum ERP of the two facilities) than that caused by SPEAR. For comparison with the setup employed for this study, the experiments at Troms $\emptyset$ utilised a heater operated with an Omode polarisation at a frequency of $4.544 \mathrm{MHz}$ with its beam pointing along the field line. The maximum effective radiated power (ERP) on these occasions was $155 \mathrm{MW}$ and the interaction (or UH) height was identified by the UHF radar to be in the altitude range $180-200 \mathrm{~km}$ (Wright et al., 2006).

The backscatter detected by the CUTLASS radars indicate that a hysteresis effect is observed and that, perhaps, the same mechanism is responsible for exciting the artificial FAIs both over Svalbard and over the Norwegian mainland. However, incoherent scatter radar measurements taken within the heated volumes over SPEAR and over the Troms $\varnothing$ heater are very different. Figure 7 is reproduced from Wright et al. (2006) and shows a typical example of hysteresis identified in ionospheric electron temperatures within the heated volume observed over Troms $\varnothing$ using the EISCAT UHF radar, over a height range which encompasses that where the artificial FAI are generated (the upper-hybrid height, as identified using the ion-line overshoot effect; e.g. Rietveld et al., 2000). Similar hysteresis was observed in changes in electron density induced by the heating effect. In contrast with these measurements, Fig. 8 illustrates the modified electron density (upper panel) and electron temperatures (lower panel) as observed by the ESR within the heated volume over SPEAR. The plotted data represent measurements averaged over all seven SPEAR cycles at the interaction height (i.e. the approximate height at which the FAI were being excited), identified by the ESR to be $158 \mathrm{~km}$. The changes in electron temperature and density plotted in Figs. 7 and 8 are relative to the measured values immediately before each heater cycle commenced. The data are again separated into those recorded during the up-going and down-going parts of the SPEAR power cycle. The averaged data are representative of the measurements over each individual cycle and demonstrate that no hysteresis was observed.

The reason why the ESR measurements are so strikingly different to those at Troms $\varnothing$ (despite the fact that the CUTLASS radar scatter suggest that the FAI are exhibiting hysteresis effects) is unclear. It is true to say that incoherent scatter radars detect signals from very different structures to those to which the coherent radars are sensitive. Also, the 


\section{EISCAT Troms $\varnothing$ UHF Radar 6 October 1997}

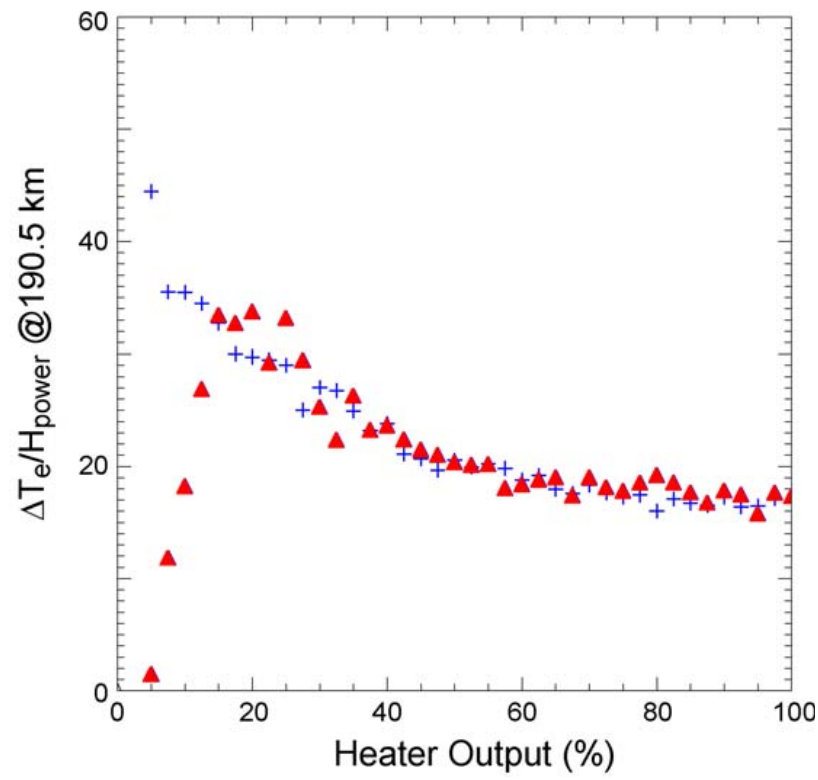

Fig. 7. The temperature change of the electrons in the ionosphere modified by the Troms $\emptyset$ heater normalised by and plotted as a function of the heater output power. Again the up- and down-going parts (respectively symbolised by $\Delta$ and + ) of the heater cycle are overlaid to illustrate the hysteresis effect (reproduced from Wright et al., 2006).

ESR transmit frequency is only half that of the mainland UHF radar. However, it seems unlikely that either of these points can explain the differences.

Other experiments undertaken utilising the ESR and SPEAR have also noted contrasts between the measurements taken at the two locations (e.g. Robinson et al., 2006). A relevant example of this is apparent in the time evolution of the parametric decay instability (PDI). At Troms $\varnothing$, when the pump wave is activated, the radio waves interact linearly with Langmuir wave modes which exist close to the reflection height of the pump wave. This initially leads to a large signal intensification observed in the ion line spectra observed by the EISCAT UHF radar. Shortly afterwards the thermal oscillating two-stream instability (TOTSI) is believed to explosively excite FAI at the upper hybrid (UH) height (below the pump wave reflection height). The FAIs then act to absorb the pump wave energy before it can reach the reflection height and thus the PDI signal is quenched. This is often called the overshoot effect. However, during SPEAR experiments on Svalbard it has been noted (Robinson et al., 2006) that the PDI signal sometimes persists for long periods and even indefinitely. However, the CUTLASS radar measurements indicate the presence of irregularities. Perhaps this indicates that the density of the artificial FAI has not saturated or is, indeed, small. In either case, the "anomalous" action

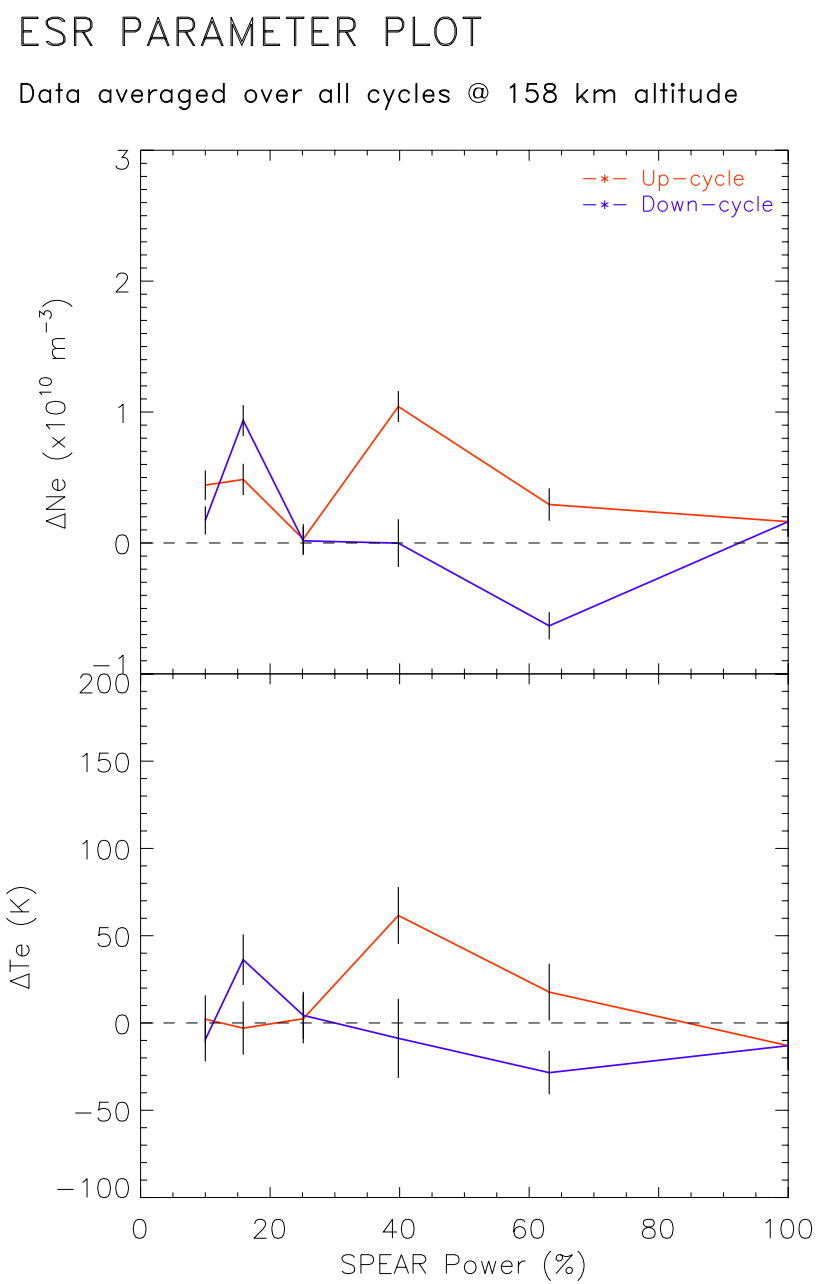

Fig. 8. Electron density (upper panel) and electron temperature (lower panel) measurements of the local ionosphere made using the ESR during the SPEAR power stepping experiment on 10 October 2006. Here the data have been averaged over all seven power cycles and are presented for the heater interaction altitude of $158 \mathrm{~km}$. The vertical black lines represent the errors bars associated with the measurements.

of the PDI over Svalbard may be consistent with the lack of observed hysteresis in the ESR measurements.

The saturated magnitude of heater-induced density striations cannot exceed a few percent (Gurevich et al., 1995) and, if the UH damping is linear, the saturated effective amplitude of the trapped UH waves should roughly be proportional to the pump amplitude. As a result, $\Delta T_{e} / T_{e 0} \sim E_{0}^{2 / 5} \sim P_{\text {pump }}^{1 / 5}$, where $\Delta T_{e} / T_{e 0}$ is the ratio of the change in electron temperature to the unperturbed electron temperature, $E_{0}$ is the electric field of the pump wave at the UH height and $P_{\text {pump }}$ is the pump power. However, below $200 \mathrm{~km}$ inelastic losses become significant in limiting $\Delta T_{e}$, especially at low heater ERP. Thus, a $30 \mathrm{~km}$ difference in altitudes between the ESR and Troms $\varnothing$ UHF radar observations (as is the case in this 
comparison) could lead to very different observed behaviour in the electron temperatures. It seems unlikely that FAIs at $158 \mathrm{~km}$ and low ERP would have reached saturation in magnitude. In addition, $\Delta T_{e}$ could be so small that it might not be detected by the ESR.

\section{Conclusion}

The SPEAR high power radar performed a power stepping experiment to investigate the properties of the ionospheric plasma over Spitsbergen, Norway. The high power radio waves excited artificial field-aligned irregularities (FAIs) which were then monitored by both CUTLASS radars and the EISCAT Svalbard Radar (ESR). It has been demonstrated that SPEAR is capable of exciting FAIs with an effective radiated power of only $1 \mathrm{MW}$, representing only 1/30th of the facility's nominal maximum output. Once the FAI are excited they are easily maintained and the threshold for collapse of the FAI was found to be less than $1 \mathrm{MW}$ but beyond the range of the experiment undertaken. The determination of this parameter will be the subject of a future experiment.

CUTLASS measurements indicated clear hysteresis in the artificially excited FAIs in that the received backscatter power from these intense ionospheric targets was higher for the power-down part of the cycle than for power-up. This agrees with observations previously made utilising the EISCAT heating facility at Troms $\varnothing$. However, incoherent scatter radar measurements made with the ESR and the UHF radar at Tromsø appear radically different. Over Svalbard, no hysteresis was observed and the measured electron densities and electron temperatures appeared chaotic within the heated volume. This is in stark contrast with observations over Troms $\varnothing$. Although this effect has been noted in other types of experiment, the reason for the difference is, as yet, unclear and is the subject of further investigation. It has been postulated that this might be the result of different physical processes dominating the ionospheric interactions in the two regions, which underlie very different magnetospheric morphologies.

Acknowledgements. This work was supported through STFC grant number PP/E000983. We are grateful to the EISCAT Scientific Association and staff at the EISCAT Svalbard Radar for their help during these experiments. DMW also thanks C. Smith for encouraging discussions relating to this paper.

Topical Editor M. Pinnock thanks M. J. Kosch and E. Mishin for their help in evaluating this paper.

\section{References}

Ashrafi, M., Kosch, M. J., and Honary, F.: Heater-induced altitude descent of the EISCAT UHF ion line enhancements: observations and modelling, Adv. Space Res., 38, 2645-2652, 2006.

Bailey, V. A. and Martyn, D. F.: Influence of electric waves in the ionosphere, Phil. Mag., 23, 369-373, 1934.
Dysthe, K. B., Mjølhus, E., Pécseli, H. L., and Rypdal, K.: A thermal oscillating two-stream instability, Phys. Fluids, 26, 146-157, 1983.

Erukimov, L. M., Metelev, S. A., Mityakov, N. A., and Frolov, V. L.: Hysteresis effect in the artificial excitation of inhomogeneities in the ionospheric plasma, Radiophysics and Quantum Electronic (Engl. Trans. of Radiofizika), 21, 1738-1741, 1978.

Fialer, P. A.: Field-aligned scattering from a heated region of the ionosphere: observations at HF and VHF, Radio Sci., 9, 923940, 1974.

Grach, S. M., Karashtin, A. N., Mityakov, N. A., Rapoport, V. O., and Trakhtengerts, V. Yu.: Thermal parametric instability in an inhomogeneous plasma (nonlinear theory), Sov. J. Plasma Phys., 4, 742-746, 1978 (Engl. Transl.).

Greenwald, R. A., Baker, K. B., Dudeney, J. R., Pinnock, M., Jones, T. B., Thomas, E. C., Villain, J.-P., Cerisier, J.-C., Senior, C., Hanuise, C., Hunsucker, R. D., Sofko, G., Koehler, J., Nielsen, E., Pellinen, R., Walker, A. D. M., Sato, N., and Yamagishi, H.: DARN/SuperDARN: a global view of the dynamics of highlatitude convection, Space Sci. Rev., 71, 761-796, 1995.

Gurevich, A. V.: Non-linear Phenomena in the Ionosphere, Springer-Verlag, New York, 1978.

Gurevich, A. V., Zybin, K. P., and Lukyanov, A. V.: Stationary striations developed in the ionospheric modification, Phys. Rev. Lett., 75, 2622-2625, 1995.

Istomin, Ya. N. and Leyser, T. B.: Small-scale magnetic fieldaligned density irregularities excited by a powerful electromagnetic wave, Phys. Plasmas, 4, 817-828, 1997.

Jones, T. B., Robinson, T., Stubbe, P., and Kopka, H.: A hysteresis effect in the generation of field-aligned irregularities by a highpower radio wave, Radio Sci., 18, 835-839, 1983.

Milan, S. E., Yeoman, T. K., Lester, M., Thomas, E. C., and Jones, T. B.: Initial backscatter occurrence statistics from the CUTLASS HF radars, Ann. Geophys., 15, 703-718, 1997, http://www.ann-geophys.net/15/703/1997/.

Minkoff, J., Kugelman, P., and Weissman, I.: Radio frequency scattering from a heated ionospheric volume, 1, VHF/UHF fieldaligned and plasma line backscatter measurements, Radio Sci., 9, 941-956, 1974.

Rietveld, M. T., Isham, B., Kohl, H., La Hoz, C., and Hagfors, T.: Measurements of HF-enhanced plasma and ion lines at EISCAT with high-altitude resolution, J. Geophys. Res., 105, 7429-7439, 2000.

Robinson, T. R.: The excitation of plasma waves and irregularities in the ionosphere by means of high power radio waves, Plas. Phys. Contr. Fusion, 30, 45-56, 1988.

Robinson, T. R.: The heating of the high latitude ionosphere by high power radio waves, Phys. Rep., 179, 79-209, 1989.

Robinson, T. R., Stocker, A. J., Bond, G. E., Eglitis, P., Wright, D. M., and Jones, T. B.: O- and X-mode heating effects observed simultaneously with the CUTLASS and EISCAT radars and low power HF diagnostics at Troms $\varnothing$, Ann. Geophys., 15, 134-136, 1997, http://www.ann-geophys.net/15/134/1997/.

Robinson, T. R., Yeoman, T. K., Dhillon, R. S., Lester, M., Thomas, E. C., Thornhill, J. D., Wright, D. M., van Eyken, A. P., and McCrea, I. W.: First observations of SPEAR-induced artificial backscatter from CUTLASS and the EISCAT Svalbard radars, Ann. Geophys., 24, 291-309, 2006, http://www.ann-geophys.net/24/291/2006/. 
Stubbe, P., Kopka, H., Lauche, H., Rietveld, M. T., Brekke, A., Holt, O., Jones, T. B., Robinson, T., Hedberg, A., Thide, B., Crochet, M. and Lotz, H. J.: Ionospheric modification experiments in northern Scandinavia, J. Atmos. Terr. Phys., 44, 1025-1041, 1982.

Stubbe, P.: Review of ionospheric modification experiments at Troms $\varnothing$, J. Atmos. Terr. Phys., 58, 349-368, 1996.

Tellegen, B. D. H.: Interaction between radio waves?, Nature, 131, 840-843, 1933.

Vaskov, V. V. and Gurevich, A. V.: Resonance instability of smallscale plasma perturbations, Sov. Phys. - JETP, 46, 487-494, 1977.

Wannberg, G., Wolf, I., Vanhainen, L.-G., Koskenniemi, K., Röttger, J., Postila, M., Markkanen, J., Jacobsen, R., Stenberg, A., Larsen, R., Eliassen, S., Heck, S., and Huuskonen, A.: The EISCAT Svalbard radar: a case study in modern incoherent scatter radar system design, Radio Sci., 32, 2283-2307, doi:10.1029/97RS01803, 1997.
Wright, D. M., Davies, J. A., Robinson, T. R., Chapman, P. J., Yeoman, T. K., Thomas, E. C., Lester, M., Cowley, S. W. H., Stocker, A. J., Horne, R. B., and Honary, F.: Space Plasma Exploration by Active Radar (SPEAR): an overview of a future radar facility, Ann. Geophys., 18, 1248-1255, 2000, http://www.ann-geophys.net/18/1248/2000/.

Wright, D. M., Davies, J. A., Yeoman, T. K., Robinson, T. R., and Shergill, H.: Saturation and hysteresis effects in ionospheric modification experiments observed by the CUTLASS and EISCAT radars, Ann. Geophys., 24, 543-553, 2006, http://www.ann-geophys.net/24/543/2006/.

Yeoman, T. K., Wright, D. M., Robinson, T. R., Davies, J. A., and Rietveld, M.: High spatial and temporal resolution observations of an impulse-driven field line resonance in radar backscatter artificially generated with the Tromsø heater, Ann. Geophys., 15, 634-644, 1997, http://www.ann-geophys.net/15/634/1997/. 